Trivent Publishing

(C) The Authors, 2016

Available online at http://trivent-publishing.eu/

Engineering and Industry Series

Volume Power Systems, Energy Markets and Renewable Energy Sources in

South-Eastern Europe

\title{
A Sensitivity Analysis of Dynamic Thermal Rating Procedures Using a Probabilistic Monte Carlo Approach
}

\author{
Paolo Pelacchi, Davide Poli \\ Department of Energy, Systems, Territory and Constructions Engineering, \\ University of Pisa, Italy; paolo.pelacchi@unipi.it, davide.poli@unipi.it
}

\begin{abstract}
The Dynamic Thermal Rating (DTR) algorithm proposed in this paper combines the CIGRE thermal model of conductors with a complex multi-span mechanical model of the line that takes into account the mechanical interaction between spans, due to the possible rotation of strings, and that the temperature of conductors can vary span by span, for different weather conditions. The developed tool is able to forecast the time trend of conductor temperatures, tensions, sags and clearances at each span. Since the weak point of DTR algorithms is the proper forecast of weather conditions about to be present on the different spans of the line, this paper investigates the possibility of using a probabilistic approach to assess the robustness of the thermal and mechanical outputs of the DTR procedure. A sensitivity analysis of results is carried out considering many different weather scenarios, properly drawn and weighted by a Monte Carlo technique. A case study based on a 400-kV overhead transmission line is shown and discussed.
\end{abstract}

\section{Keywords}

Dynamic Thermal Rating; Monte Carlo procedures; Overhead lines.

This is an Open Access article distributed in accordance with the Creative Commons Attribution Non Commercial (CC-BY-NC-ND 4.0) license, which permits others to copy or share the article, provided original work is properly cited and that this is not done for commercial purposes. Users may not remix, transform, or build upon the material and may not distribute the modified material (http://creativecommons.org/licenses/by-nc/4.0/) 


\section{Introduction}

The power flow limits of transmission lines are set so as to ensure a given level of security in the electric system; an improper definition of these limits can increase the disconnection of renewable generators [1], or barriers to the free trading of energy, with the consequent onset of zonal prices.

Both for planning and operation purposes, the most important constraint to be respected in an Over Head Transmission Line (OHTL) is providing adequate clearances to the objects placed under the line, at all operating conditions; this is the primary aspect that limits the rating ("ampacity") of a line [2].

The thermal rating of a transmission line is the highest current that the line can carry under assigned meteorological conditions, respecting all clearances. The ampacity is limited in practice by the maximum allowed operating temperature: if the temperature limit is exceeded, the distances between conductors and ground decrease to unacceptable values. As a consequence, the compliance with safety and reliability codes may be violated [3].

In this context, Dynamic Thermal Rating (DTR) of transmission lines represents a significant improvement with respect to the traditional steady-state rating criteria, which usually result in standard seasonal ampacities. This is because DTR uses actual operating conditions of the power line, rather than assumed conservative conditions or historical averages [4].

Dynamic Thermal Rating is not only attractive for defining the real ampacity of power lines in reliability studies, but also extremely promising for the secure operation of electric systems by TSOs. In fact the thermal time constant of conductors is relatively high (more than 10 minutes); this consideration allows exploiting the dynamic performances of conductors, i.e. currents significantly higher than the steady-state thermal limits, in the meantime that the system is redispatched [5]. This strategy is a valid alternative to the expensive installation of new assets like power lines or storage devices [6][7][8] and can reduce redispatching costs, enhance system reliability and minimize the curtailment of renewable energy sources [9][10].

Assessing the dynamic ampacity of a power line means understanding how long the line can carry a given current respecting all ground clearances or, viceversa, which current can be carried for a given time. The margin of dynamic overloading of a power line can be assessed focusing on the temperature of the conductor; such a temperature can be either evaluated using a thermal model, having as an input weather conditions and power flow, or operating a direct measure on the conductor [11].

The analysis of the literature clearly shows that, regardless which method is used to estimate the conductor temperature, the dynamic mechanical behaviour of power lines has been so far investigated under the hypothesis that the horizontal mechanical tension along the line is uniform [12]; this means neglecting the contribution given to the tensions, span by span, by the insulators' strings rotation. This technique is referred to as method of the "ruling span technique" [13][14]. 
Conversely, it is well known that in a real multi-span line with different span lengths, armed by insulator strings (I or V) that support the same conductor, longitudinal displacements arise due to different conductor stress in each span [16].

The present paper proposes a novel dynamic thermo-mechanical model of multi-span power lines, for purposes of Dynamic Thermal Rating, which takes into account:

- the actual weather conditions (wind, sun, ambient temperature), hence the real conductor temperature, at each single span of the power line;

- the vertical components of mechanical tension of conductors for each insulator string;

- the actual horizontal component of mechanical tension, span by span;

- the mechanical interaction between adjacent spans.

The weakest point of all DTR algorithms that estimate the temperature of the conductor, instead of measuring it, is the proper forecast of weather conditions (such as irradiance, direction and speed of wind) about to be present on the different spans of the line. For these reasons, this paper also investigates the possibility of using a probabilistic Monte Carlo approach to assess the robustness of the thermal and mechanical outputs of the proposed DTR procedure. A sensitivity analysis of results is carried out considering many different weather scenarios, properly drawn and weighted by a Monte Carlo technique.

A case study based on a $400-\mathrm{kV}$ overhead transmission line is shown and discussed.

\section{Thermo-mechanical model of a multi-span OHTL}

A multi-span line is defined as the part of the power line existing between two dead-end towers. As remarked before, the thermal and mechanical phenomena are interactive, but their time constants are very different (about two orders of magnitude). For these reasons, the two phenomena can be disaggregated; this means that the solution of the model will be subdivided into two steps:

1. The dynamic evaluation of the temperature of conductors over time, based on power flow and weather conditions (span by span);

2. The algebraic evaluation of the mechanical equilibrium of the multispan line at each time step, the temperature of conductors being known.

\section{A. Thermal analysis}

There is a wide literature dealing with the thermal behaviour of OHTL conductors. The two more relevant documents are [17] and [18]. They basically differ only for marginal phenomena, like corona losses, and for a different formulation of heat transfer due to forced and natural convection. 
In our case, the dynamic behaviour of conductor temperature has been evaluated using the CIGRE model [17]; the calculations are carried out as a function of line current, conductor thermal properties and weather conditions (ambient temperature, solar radiation, wind speed, etc.). All these parameters are considered variable over time and different span by span.

The thermal equilibrium between a conductor and the surrounding environment is governed by the following differential equation, valid in the case of homogeneous and isotropic body at uniform temperature:

$$
P_{t}=C_{t} \frac{d \vartheta^{\Delta}}{d t}+\lambda A 9^{\Delta}
$$

where:

- $\mathrm{P}_{\mathrm{t}}$ is the thermal power applied to the conductor (Joule losses, solar radiation, magnetic losses and corona);

- $\mathrm{C}_{\mathrm{t}}$ is the heat capacity of the conductor (product of mass and specific heat);

- $\vartheta^{\Delta}=\vartheta-\vartheta_{\text {amb }}$ is the temperature of the conductor with respect to the environment;

- $\lambda$ is the overall coefficient of heat transfer from the conductor to the external environment; it depends on convection, radiation and, in the case of wet conductor, evaporation phenomena;

- A is the heat exchange surface.

The term $C_{t} d 9 / d t$ expresses the contribution of the thermal power to the increase of the temperature of the conductor, while the term $\lambda \vartheta^{\Delta}$ represents the heat that is transferred to the environment per unit of time.

At steady-state regime, the temperature is constant and the term $C_{t} \frac{d \vartheta^{\Delta}}{d t}$ is null:

$$
\begin{aligned}
& P_{t}=\lambda A \vartheta_{\text {std }}^{\Delta} \\
& \vartheta_{\text {std }}^{\Delta}=\frac{P_{t}}{\lambda \mathrm{A}} \\
& \vartheta_{\text {std }}=\vartheta_{\text {amb }}+\vartheta_{\text {std }}^{\Delta}=\vartheta_{\text {amb }}+\frac{P_{t}}{\lambda \mathrm{A}}
\end{aligned}
$$

where $\vartheta_{\text {std }}$ is the steady-state temperature of the conductor. During the firstorder transient, the resolution of the differential Eq. (1) leads to the following change in temperature ("heating curve"):

$$
\vartheta(\mathrm{t})=\vartheta_{0}+\left(\vartheta_{\mathrm{std}}-\vartheta_{0}\right) \cdot\left(1-\mathrm{e}^{-\mathrm{t} / \tau}\right)
$$

or:

$$
\vartheta(t)=\vartheta_{\text {std }}-\left(\vartheta_{\text {std }}-\vartheta_{0}\right) \cdot \mathrm{e}^{-\mathrm{t} / \tau}
$$


where $\vartheta_{0}=\vartheta_{(t=0)}$ is assumed to be known, $\tau=R_{t} C_{t}$ is the thermal time constant ( $1^{\text {st }}$-order system), and $\mathrm{R}_{\mathrm{t}}=1 /(\lambda \mathrm{A})$ is the thermal resistance associated with the exchange of heat between the conductor and the surrounding environment.

If the initial temperature of the conductor $\vartheta_{0}$ and its maximum tolerable temperature $\vartheta_{\max }$ are known, this latter basically depending on clearances, the time trend of conductor temperature in response to a step of current is depicted in Fig.1.

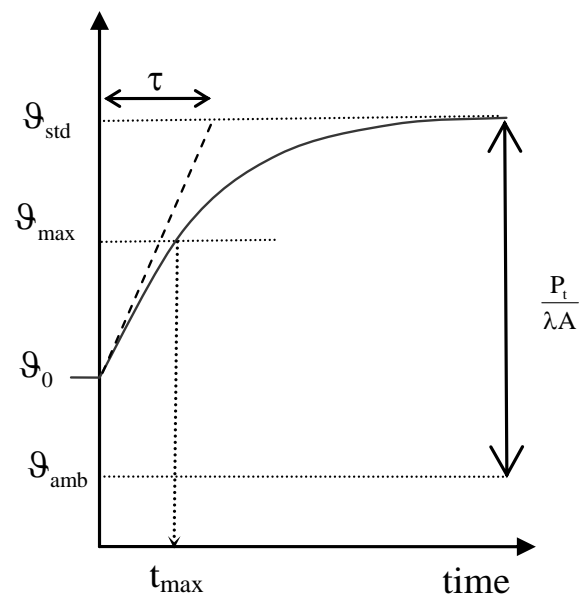

Fig. 1. Heating curve and margin of overloading

The maximum permissible duration of the overload, $\mathrm{t}_{\max }$, depends on:

- the available temperature margin $\left(\vartheta_{\max }-\vartheta_{0}\right)$;

- the power $\mathrm{P}_{\mathrm{t}}$, which using Eq. (4) determines the steady-state temperature $\vartheta_{\text {std }}$

- the thermal time constant $\tau$.

The CIGRE document reports calculation methods for $\lambda$ and $\tau$, taking into account thermo-fluid dynamic considerations; the calculation, based on the equilibrium between heat entering in the conductor and heat dispersed to the environment, is iterative, since $\lambda$ itself depends on the steady-state conductor temperature. In previous papers of the same authors [19][20], new thermal models have been proposed and discussed also for High Temperature Low Sag conductors [21][22].

The dynamic solution of the thermal problem is found by applying a sampleand-hold procedure to the time trend of inputs (current, solar radiation, intensity and direction of wind, ambient temperature, all sampled for instance every 5 minutes) and consequently studying the time trend of conductor temperature, separately span by span, as sequence of first-order step responses. 
The temperatures obtained along the line are then used, separately at each time step (e.g. every minute), to solve the algebraic mechanical problem.

\section{B. Mechanical equilibrium of conductors}

In a conventional line with self-supporting towers, the mechanical analysis of the conductors under the action of internal and external agents can be carried out simply on one single phase, the one closer to the ground.

The different load conditions of the conductors with respect to the reference condition (typically the Every Day Stress condition, EDS) produce span by span stress variations in the conductors; such variations, depending on the length and weight of the insulators strings, produce a new longitudinal asset of the line and, therefore, a new mechanical equilibrium that is in general different from the one considered at the design phase. In order to analyze the line behaviour under electrical overload conditions, which can persist from fifteen minutes up to a few hours, it is important to use a model that takes in to account the movement of the insulators strings.

Assuming that the mass of the conductor between two insulator's string clamps remains constant, we can impose that the variation in length between the initial condition and the derived one, due to thermal elongation, conductor elasticity and change in the distance between the clamps, must match the variation calculated as the development of the length of the conductor along the span.

In particular, under the usual approximation of the catenary to a parabola, we can write:

$$
\alpha\left(\vartheta_{1}-\vartheta_{0}\right) \mathrm{d}+\frac{\left(\mathrm{s}_{1}-\mathrm{s}_{0}\right)}{\mathrm{E}} \mathrm{d}+\Delta l=\left(\mathrm{d}+\frac{\mathrm{q}_{1}^{2} \mathrm{~d}^{3}}{24 \cdot \mathrm{s}_{1}^{2}}\right)-\left(\mathrm{d}+\frac{\mathrm{q}_{0}^{2} \mathrm{~d}^{3}}{24 \cdot \mathrm{s}_{0}^{2}}\right)
$$

where subscripts 0 and 1 respectively represent the reference and a generic load condition, and:

$\alpha \quad$ coefficient of linear thermal expansion $\left[{ }^{\circ} \mathrm{C}^{-1}\right]$

d horizontal span length [m]

$\Delta l \quad$ conductor elongation for clamps displacement [m]

$\vartheta_{0} \quad$ conductor temperature (initial condition) $\left[{ }^{\circ} \mathrm{C}\right]$

$\vartheta_{1} \quad$ conductor temperature (derived condition) $\left[{ }^{\circ} \mathrm{C}\right]$

E Young's elasticity modulus $\left[\mathrm{N} / \mathrm{m}^{2}\right]$

$\mathrm{q}_{0} \quad$ conductor weight per unit of length (initial condition) $\left[\mathrm{N} /\left(\mathrm{mm}^{2} \mathrm{~m}\right)\right]$

$\mathrm{q}_{1} \quad$ conductor weight per unit of length (derived condition) $\left[\mathrm{N} /\left(\mathrm{mm}^{2} \mathrm{~m}\right)\right]$

$\mathrm{s}_{0} \quad$ conductor stress (initial condition) $\left[\mathrm{N} / \mathrm{mm}^{2}\right]$

$\mathrm{s}_{1} \quad$ conductor stress (derived condition) $\left[\mathrm{N} / \mathrm{mm}^{2}\right]$ 
Weights per unit of length take into account also the effect of wind and ice. Rearranging Eq. (7) as a function of conductor stress $s_{1}$ under derived condition, we obtain the "equation of change of state:"

$$
\mathrm{s}_{1}^{3}-\mathrm{s}_{1}^{2} \cdot\left[\mathrm{s}_{0}-\mathrm{E}\left(\frac{\Delta l}{\mathrm{~d}}+\alpha\left(\vartheta_{1}-\vartheta_{0}\right)+\frac{\mathrm{q}_{0}^{2} \mathrm{~d}^{2}}{24 \cdot \mathrm{s}_{0}^{2}}\right)\right]-\frac{\mathrm{q}_{1}^{2} \mathrm{~d}^{2} \mathrm{E}}{24}=0
$$

Usually all quantities related to the reference condition (subscript 0) are known (e.g. EDS).

Moreover, the thermal analysis provides the temperature $\vartheta_{1}$ of the conductor, while $\mathrm{q}_{1}$ differs from $\mathrm{q}_{0}$ only with different wind or ice. In case of a single span delimited by two dead-end towers, Eq. (8) is then enough to solve the mechanical problem, since $\Delta l$ is null and the only unknown quantity is $s_{1}$.

In case of more spans between two dead-end towers, for each span an equation like Eq. (8) can be written, but terms $\Delta l$ are not null. These terms can be expressed as a function of the angles formed by insulator strings in the derived condition, with respect to the EDS configuration (where strings are vertical).

Such angles constitute, together with terms $s_{1}$ of each span, the unknown quantities of the mechanical problem.

The other equations that must be considered to solve the problem express the equilibrium of the strings of insulators. In particular, for an I-string we have (equilibrium along the three axes):

$$
\begin{aligned}
& \mathrm{F}_{x, i}+\left(\mathrm{n}_{i-1} \cdot \mathrm{s}_{i-1}+\mathrm{n}_{i} \cdot \mathrm{s}_{i}\right) \cdot \operatorname{sen} \frac{\gamma_{i}}{2}=0 \\
& \mathrm{~F}_{y, i}+\left(-\mathrm{n}_{i-1} \cdot \mathrm{s}_{i-1}+\mathrm{n}_{i} \cdot \mathrm{s}_{i}\right) \cdot \cos \frac{\gamma_{i}}{2}=0 \\
& \mathrm{~F}_{z, i}+\left(\mathrm{n}_{i-1} \cdot \mathrm{s}_{i-1} \cdot \tan \beta_{i-1}+\mathrm{n}_{i} \cdot \mathrm{s}_{i} \cdot \tan \beta_{i}\right)=0
\end{aligned}
$$

and (rotational equilibrium of the string):

$$
\begin{aligned}
& {\left[\left(\mathrm{F}_{x, i} \cdot \operatorname{sen} \phi_{i}+\mathrm{F}_{z, i} \cdot \cos \phi_{i}\right) \cdot \operatorname{sen} \delta_{i}-\mathrm{F}_{y, i} \cdot \cos \delta_{i}\right] \cdot \mathrm{L}_{i}=0} \\
& {\left[\left(\mathrm{~F}_{y, i} \cdot \operatorname{sen} \delta_{i}+\mathrm{F}_{z, i} \cdot \cos \delta_{i}\right) \cdot \operatorname{sen} \phi_{i}-\mathrm{F}_{x, i} \cdot \cos \phi_{i}\right] \cdot \mathrm{L}_{i}=0}
\end{aligned}
$$

where:

$\mathrm{i} \quad$ is the considered insulator string

$\mathrm{F}_{\mathrm{x}, \mathrm{i}}$ is the concentrated force applied along $\mathrm{x}$-axis $[\mathrm{N}]$;

$\mathrm{F}_{\mathrm{y}, \mathrm{i}}$ is the concentrated force applied along y-axis $[\mathrm{N}]$;

$\mathrm{F}_{\mathrm{z}, \mathrm{i}} \quad$ is the concentrated force applied along $\mathrm{z}$-axis $[\mathrm{N}]$;

$\mathrm{L}_{\mathrm{i}} \quad$ is the length of the $\mathrm{i}$-th string [m];

$n_{i} \quad$ is the number of conductors per phase. 
Concentrated forces $\mathrm{F}_{\mathrm{i}}$ are known. Their components along $\mathrm{x}$ and $\mathrm{y}$ axes are usually null; $F_{z, i}$ is due to half the weight of the string, half the weight of the conductors at the two sides of the string, plus an external weight if present.

The meaning of angles of Eq. (9) and Eq. (10) is explained in Figures 2 and 3. More details are in [23] and [24]. In case of V-strings, angles $\phi_{1}$ are null.
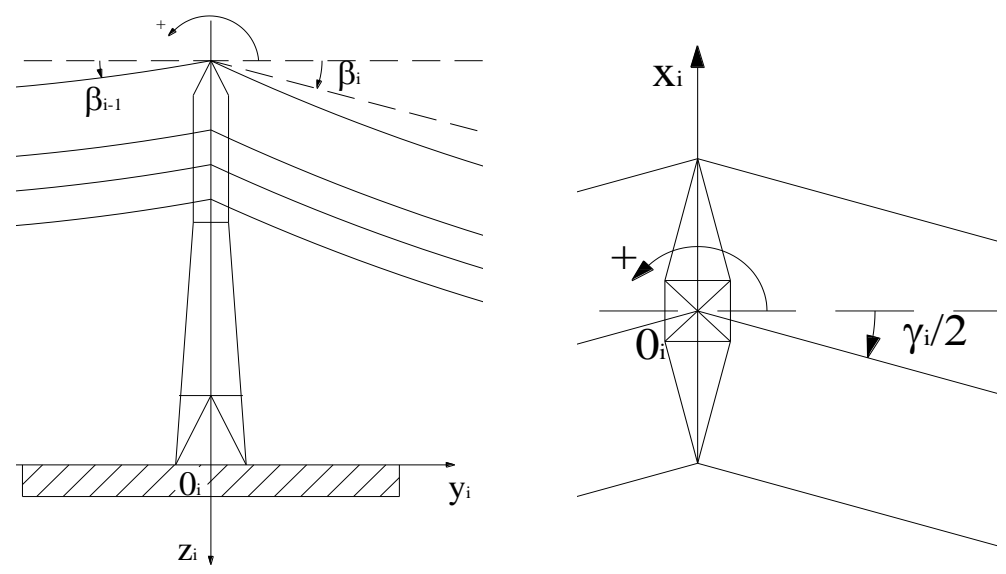

Fig. 2. Lateral and top view of the tower

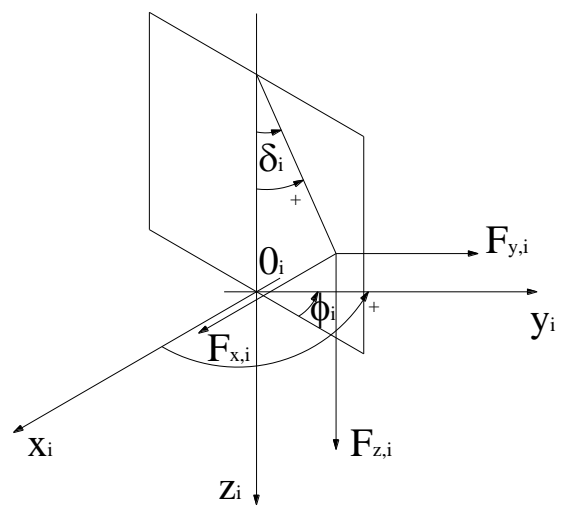

Fig. 3. The string of insulators in a Cartesian coordinate system

\section{Numerical solution of the problem}

A computer program has been developed in order to evaluate the time domain response of the thermal and mechanical behaviour of an overhead power line under electrical and weather solicitations. This tool requires as input the OHTL structural data (span lengths, conductor and insulators' strings characteristics, line angles, etc.) in addition to other time varying operating conditions data (current, atmospheric temperature, wind speed in direction and intensity, solar radiation, etc.). 
The program generates, span by span, the time trend of conductor temperatures and, subsequently, of horizontal stress, which is required to calculate sags.

The tool can work in two different modes:

a) Free Evolution mode: the software determines the time trend of temperature and sags of the conductors, span by span, over a time horizon t' (e.g. three hours);

b) Maximum Current mode: the software calculates the maximum current sustainable for an assigned time t" (for instance 30 minutes) without a violation of a constraint (e.g.: maximum temperature and/or sag are exceeded). A dichotomous technique is used.

\section{Case study}

In previous papers of the same authors, the described thermo-mechanical model was applied to compare the steady state and the dynamic performance of conductors [23][24], or to estimate the calculation errors induced by the simplified "ruling span" technique [19][20].

The present case study is instead focused on the possible impact of weather forecasting accuracy on the temperatures and sags of a transmission line. As a matter of fact, the incertitude associated to weather parameters, such as irradiance, ambient temperature, wind speed and direction, can affect the right calculation of the temperature of the conductor, hence its sag and the thermal rating of the line.

Traditional sensitivity analyses are usually deterministic, since they assume some independent scenarios of input quantities (in our case, weather parameters) and assess the correspondent variation of output values (here temperatures and sags). In this paper, a probabilistic approach is conversely proposed, in order to assign a proper weight to each weather scenario. For this reason, a given frequency distribution is associated to each weather parameter, then the correspondent frequency distribution of temperatures and sags is calculated according to a Monte Carlo procedure. To this purpose, the thermal and the mechanical models previously described have been implemented in Excel ${ }^{\circledR}$ and made probabilistic with the tool Crystal Ball ${ }^{\circledR}$.

Table 1 reports the 18 analysed cases. Variations with respect to the base case (case n.1) are highlighted in bold. All distribution functions of weather parameters are Gaussian, except for the values marked with a "w," for whom a Weibull function was assumed to avoid negative values of wind speed. For each case, 1.000 .000 weather conditions drawn by the Monte Carlo procedure were provided to the thermal model of the conductor described in Table 2, supposed to carry $1000 \mathrm{~A}$. 
Table 1. Weather scenarios

\begin{tabular}{|c|c|c|c|c|c|c|c|c|}
\hline \multirow{2}{*}{ ঠ్ } & \multicolumn{2}{|c|}{$\begin{array}{c}\text { Solar irradiance } \\
{\left[\mathrm{W} / \mathbf{m}^{2}\right]}\end{array}$} & \multicolumn{2}{|c|}{$\begin{array}{l}\text { Ambient } \\
\text { temp. }\left[{ }^{\circ} \mathrm{C}\right]\end{array}$} & \multicolumn{2}{|c|}{$\begin{array}{c}\text { Wind } \\
\text { speed }[\mathrm{m} / \mathrm{s}]\end{array}$} & \multicolumn{2}{|c|}{$\begin{array}{c}\text { Wind } \\
\text { direction } \\
\text { w.r.t. the line }\left[^{\circ}\right]\end{array}$} \\
\hline & $\frac{\Sigma}{\tilde{z}}$ & 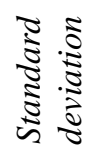 & $\underset{\mathbb{Z}}{\tilde{\Xi}}$ & 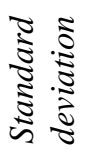 & $\underset{\Xi}{\mathbb{Z}}$ & 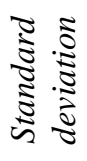 & $\frac{\mathfrak{z}}{\tilde{z}}$ & 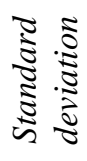 \\
\hline 1 & 1000 & 50 & 30 & 0.5 & 3 & 0.5 & 90 & 10 \\
\hline 2 & 700 & 50 & 30 & 0.5 & 3 & 0.5 & 90 & 10 \\
\hline 3 & 700 & 150 & 30 & 0.5 & 3 & 0.5 & 90 & 10 \\
\hline 4 & 1000 & 50 & 45 & 0.5 & 3 & 0.5 & 90 & 10 \\
\hline 5 & 1000 & 50 & 45 & 2 & 3 & 0.5 & 90 & 10 \\
\hline 6 & 1000 & 50 & 10 & 0.5 & 3 & 0.5 & 90 & 10 \\
\hline 7 & 1000 & 50 & 10 & 2 & 3 & 0.5 & 90 & 10 \\
\hline 8 & 1000 & 50 & 30 & 0.5 & $3 w$ & $2 w$ & 90 & 10 \\
\hline 9 & 1000 & 50 & 30 & 0.5 & 6 & 0.5 & 90 & 10 \\
\hline 10 & 1000 & 50 & 30 & 0.5 & 6 & 2 & 90 & 10 \\
\hline 11 & 1000 & 50 & 30 & 0.5 & $2 w$ & $0.5 \mathrm{w}$ & 90 & 10 \\
\hline 12 & 1000 & 50 & 30 & 0.5 & $\mathbf{1 w}$ & $0.5 \mathrm{w}$ & 90 & 10 \\
\hline 13 & 1000 & 50 & 30 & 0.5 & 3 & 0.5 & 90 & 45 \\
\hline 14 & 1000 & 50 & 30 & 0.5 & 3 & 0.5 & 45 & 10 \\
\hline 15 & 1000 & 50 & 30 & 0.5 & 3 & 0.5 & 45 & 45 \\
\hline 16 & 1000 & 50 & 30 & 0.5 & 3 & 0.5 & $\mathbf{0}$ & 10 \\
\hline 17 & 1000 & 50 & 30 & 0.5 & 3 & 0.5 & $\mathbf{0}$ & 45 \\
\hline 18 & 800 & 200 & 30 & 5 & $3 w$ & $2 w$ & 45 & 45 \\
\hline
\end{tabular}

Table 2. Conductor features

\begin{tabular}{|l|l|l|}
\hline Feature & Unit & Value \\
\hline External diameter & $\mathrm{mm}$ & 31.5 \\
\hline Total section & $\mathrm{mm}^{2}$ & 585.3 \\
\hline Internal layer section (steel) & $\mathrm{mm}^{2}$ & 65.8 \\
\hline External layer section (aluminum) & $\mathrm{mm}^{2}$ & 519.5 \\
\hline Unitary mass & $\mathrm{kg} / \mathrm{m}$ & 1.95 \\
\hline Resistance & $\Omega / \mathrm{km}^{\circ}$ & 0.0564 \\
\hline Internal layer thermal capacity & $\mathrm{J} / \mathrm{kg}^{\circ} \mathrm{C}$ & 481 \\
\hline External layer thermal capacity & $\mathrm{J} / \mathrm{kg}^{\circ} \mathrm{C}$ & 897 \\
\hline Internal layer elasticity & $\mathrm{daN} / \mathrm{mm}^{2}$ & 13100 \\
\hline External layer elasticity & $\mathrm{daN} / \mathrm{mm}^{2}$ & 6000 \\
\hline Internal layer thermal elongation & ${ }^{\circ} \mathrm{C}^{-1}$ & $4.7 \mathrm{E}-6$ \\
\hline External layer thermal elongation & ${ }^{\circ} \mathrm{C}^{-1}$ & $2.1 \mathrm{E}-5$ \\
\hline
\end{tabular}

Table 3 reports the results in terms of steady state conductor's temperature. The deterministic temperature shown in the first column is calculated at the 
average value of weather parameters; since the thermal model is non linear with respect to weather parameters, also when the input distribution function is symmetric (Gaussian) the deterministic temperature, its probabilistic mean and median do not correspond. The minimum and maximum conductor's temperatures obtained with the one million trials of the probabilistic procedure are also reported.

The most significant parameter to capture the variability of the conductor's temperature is the standard deviation, which spans from $3{ }^{\circ} \mathrm{C}$ in the base case to around $18^{\circ} \mathrm{C}$ in Case 18 , where the weather incertitude is extreme. The highest standard deviations are underlined.

Fig.4 show the distribution function of the conductor's temperature obtained in the weather base case. The best fit of this distribution is a Lognormal function, also plotted in the same figure. Fig.5 show what happens in Case 12, where the wind speed is lower, so both natural cooling (conductor's temperatures higher than $90^{\circ} \mathrm{C}$ ) and forced cooling (wind speed above $0.5 \mathrm{~m} / \mathrm{s}$ ) can occur.

Table 3. Thermal results: steady state conductor's temperature

\begin{tabular}{|c|c|c|c|c|c|c|}
\hline$\underbrace{\mathscr{W}}_{\tilde{J}}$ & 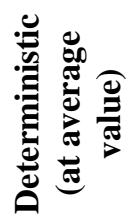 & 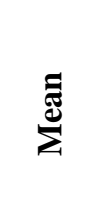 & 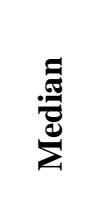 & $\underset{\Sigma}{. \Xi \Xi}$ & 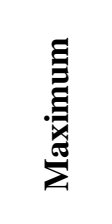 & 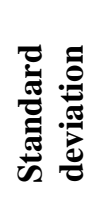 \\
\hline 1 & 49.56 & 50.12 & 49.73 & 41.76 & 77.38 & 2.92 \\
\hline 2 & 48.4 & 48.92 & 48.56 & 40.93 & 74.74 & 2.74 \\
\hline 3 & 48.4 & 48.92 & 48.56 & 40.13 & 74.86 & 2.8 \\
\hline 4 & 65.72 & 66.3 & 65.9 & 57.44 & 96.29 & 3 \\
\hline 5 & 65.72 & 66.3 & 66.03 & 52.47 & 107.63 & 3.65 \\
\hline 6 & 27.87 & 28.4 & 28.03 & 20.67 & 58.98 & 2.75 \\
\hline 7 & 27.87 & 28.4 & 28.16 & 14.58 & 63.62 & 3.46 \\
\hline 8 & 49.56 & 55.8 & 51.83 & 34.01 & 121.88 & 14.5 \\
\hline 9 & 41.28 & 41.43 & 41.39 & 37.47 & 47.99 & $\overline{0.95}$ \\
\hline 10 & 41.28 & 42.74 & 41.4 & 34.39 & 121.94 & 5.95 \\
\hline 11 & 61.63 & 57.62 & 56.78 & 45.16 & 108.57 & 5.19 \\
\hline 12 & 68.59 & 73.21 & 69.74 & 44.73 & 122.35 & 12.92 \\
\hline 13 & 49.56 & 53.81 & 52.05 & 42.08 & 111.9 & 6.44 \\
\hline 14 & 53.09 & 53.86 & 53.35 & 41.61 & 86.94 & 3.95 \\
\hline 15 & 53.09 & 56.31 & 54.02 & 41.67 & 116.65 & 7.87 \\
\hline 16 & 74.92 & 69.28 & 68.88 & 47.87 & 119.18 & 6.77 \\
\hline 17 & 74.92 & 58.92 & 57.11 & 42.46 & 107.97 & 8.44 \\
\hline 18 & 52.95 & 61.85 & 58.24 & 19.92 & 132.3 & 17.86 \\
\hline
\end{tabular}




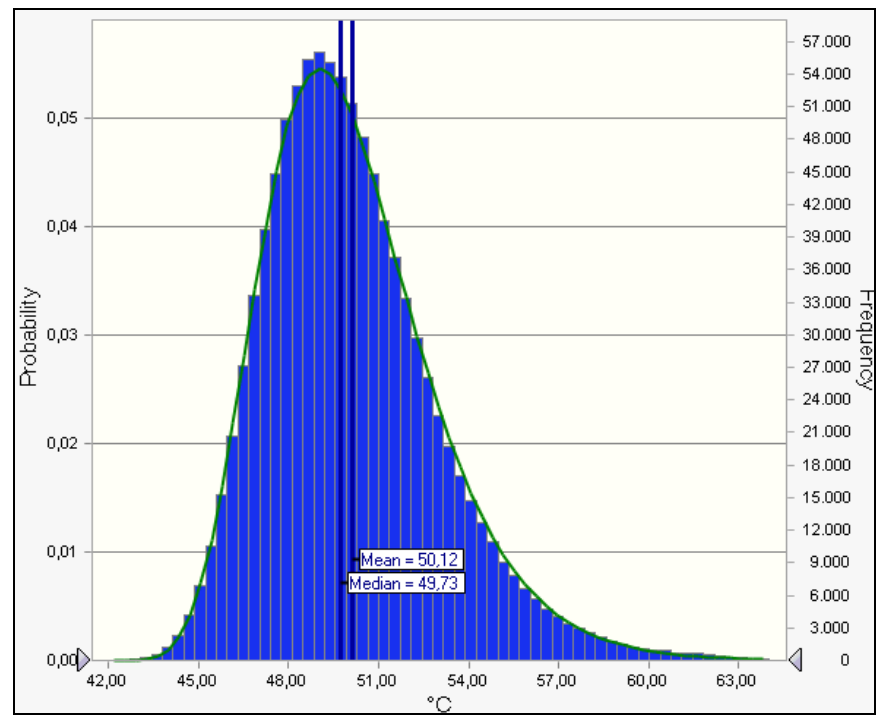

Fig. 4. Distribution function of conductor's temperature - Case 1

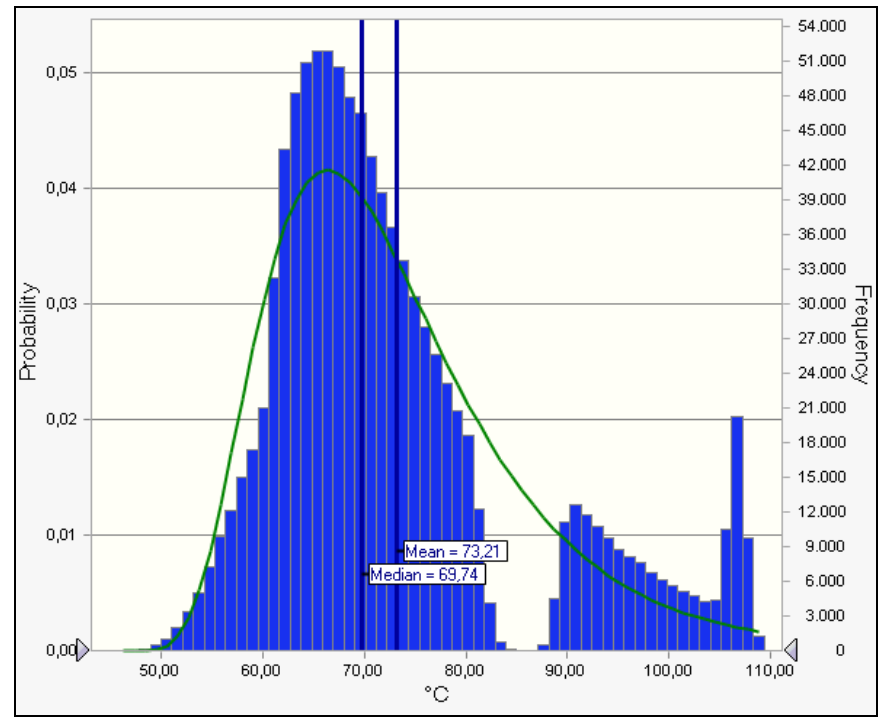

Fig. 5. Distribution function of conductor's temperature - Case 12

The mechanical model of the transmission line described in Table 4 was then fed by the temperatures provided by the thermal model, in order to analyze the correspondent variability of sags. 
Table 4. Transmission line features

\begin{tabular}{|l|l|l|}
\hline Feature & Unit & Value \\
\hline Elevation a.s.l. & $\mathrm{m}$ & 300 \\
\hline Total conductor's EDS & $\mathrm{daN}$ & 2400 \\
\hline Internal layer EDS & $\mathrm{daN}$ & 515 \\
\hline External layer EDS & $\mathrm{daN}$ & 1885 \\
\hline EDS temperature & ${ }^{\circ} \mathrm{C}$ & 15 \\
\hline Insulators strings' length & $\mathrm{m}$ & 3 \\
\hline Length between 2 dead-end towers & $\mathrm{m}$ & 3080 \\
\hline Spans between 2 dead-end towers & & 7 \\
\hline Length of spans \#1, 2,3, 5,6,7 & $\mathrm{m}$ & 380 \\
\hline Length of span \#4 & $\mathrm{m}$ & 800 \\
\hline
\end{tabular}

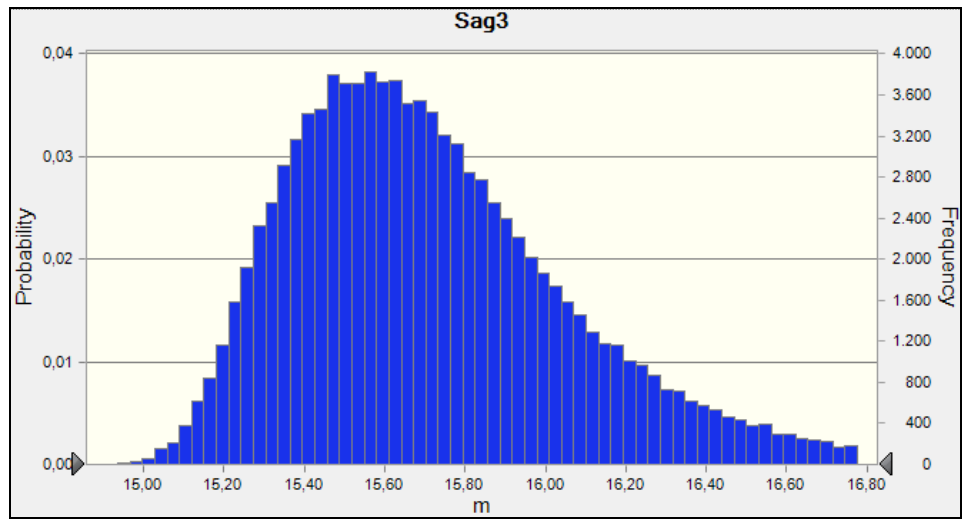

Fig. 6. Distribution function of the sag calculated at the shortest span

With reference to Case 18, where the incertitude about weather parameters is maximum, Fig. 6 and 7 report the distribution function of sag respectively at shortest and longest span. The standard deviation of sags is rather low, respectively $0.37 \mathrm{~m}(2.3 \%)$ and $0.83 \mathrm{~m}(1.2 \%)$ in the two considered spans. 


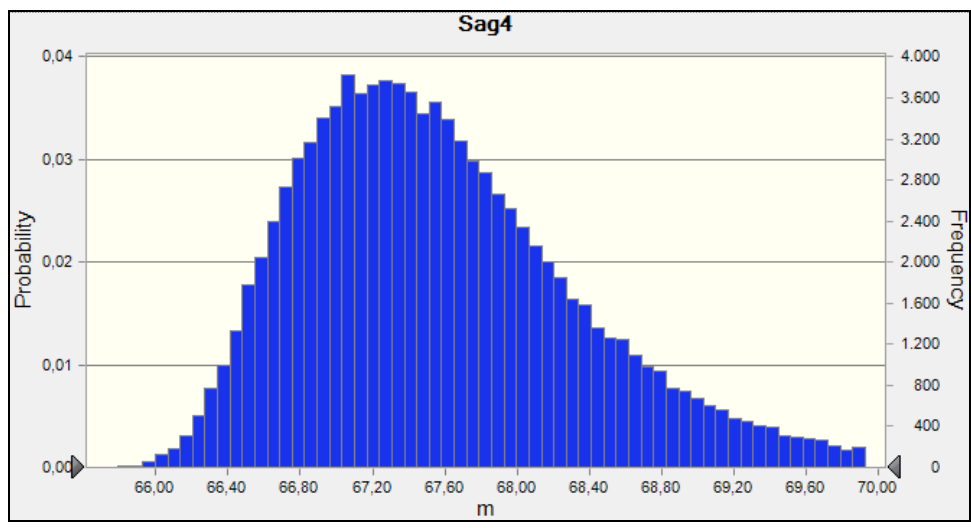

Fig. 7. Distribution function of the sag calculated at the longest span

\section{Conclusions}

This paper proposes a new thermo-mechanical model able to calculate the temperature and the consequent sag of each span of an overhead transmission line, as a function of weather parameters existing along the path.

The calculations performed in the paper demonstrate that the incertitude associated with the weather forecasting has a significant impact on the scattering of thermal quantities; in fact, in the most volatile weather scenario the standard deviation of the distribution function that describes the conductor's temperature can reach a couple of tens of Celsius degrees.

The weather parameter that mostly affects the temperature of the conductor is the wind speed, whose incertitude significantly enhances the variability of temperatures and sags. This happens especially if the average value of wind speed is lower then $3-4 \mathrm{~m} / \mathrm{s}$, when a small variation in wind speed has a strong impact on the temperature of the conductor; conversely, over $5 \mathrm{~m} / \mathrm{s}$ the significant cooling effect pushes the conductor's temperature towards the ambient temperature, regardless of the exact value of wind speed.

Fortunately, even when the variability of the temperature of the conductor is extreme, the calculations performed show that the mechanical quantities (strengths and sags) remain rather predictable. With reference to the transmission line under investigation, the standard deviation of sag is only around $40 \mathrm{~cm}$ and $80 \mathrm{~cm}$, respectively in the shortest and longest span, their average sag being around $15 \mathrm{~m}$ and $67 \mathrm{~m}$.

This confirms the validity of DTR approaches based on an estimation of conductor's temperature rather than on a direct measure of thermal or mechanical quantities.

\section{Acknowledgement}

The project presented in this paper was partially supported by TERNA, the Italian TSO. 


\section{References}

[1] R. Giglioli, D. Poli. "Small-scale biomass-fired cogeneration, pellet production or district heating: new criteria for selecting the most profitable solution", International Review on Modelling and Simulations, IREMOS 6 (2013).

[2] D.P. Popović. "An efficient unified methodology for steady-state security assessment of electric power interconnection", International Review of Electrical Engineering, 5 (2010).

[3] M. Giuntoli, P. Pelacchi, D. Poli. "On the use of simplified reactive power flow equations for purposes of fast reliability assessment", IEEE EUROCON 2013, Zagreb, Croatia, 1-4 July 2013.

[4] J.R. Santos, A. Gomez, F. Parreno. "Assessment of conductor thermal models for grid studies”, IET Gen.,Transmission, Distribution 1 (2007).

[5] M. Giuntoli, D. Poli. "On the possible use of probabilistic techniques for purposes of short-term load dispatching", International Review of Electrical Engineering, IREE 8 (2013).

[6] S. Barsali, M. Ceraolo, R. Giglioli, D. Poli. "Storage applications for smartgrids", Electric Power System Research (EPSR), 120 (2015): 109117.

[7] M. Ceraolo, G. Lutzemberger, M. Funaioli, L. Sani, D. Poli. "Electrical Storage for the Enhancement of Energy and Cost Efficiency of Urban Railroad Systems", The second International Conference on Railway Technology, Ajaccio, 8-11 April 2014.

[8] D. Poli, A. Di Donato, G. Lutzemberger. "Experiences in modelling and simulation of hydrogen fuel-cell based propulsion systems", $9^{\text {th }}$ International Conference on Engines \& Vehicles - ICE2009, Capri 13-18 September 2009.

[9] R. Adapa, D.A. Douglass. "Dynamic Thermal Ratings: Monitors and calculation methods", IEEE PES 2005, Durban, July 2005.

[10] M. Giuntoli, D. Poli. "Optimized thermal and electrical scheduling of a Large Scale Virtual Power Plant in the presence of energy storages", IEEE Transactions on Smart Grid 4 (2013).

[11] J. Heckenbergerová, J. Hošek. "Dynamic thermal rating of power transmission lines related to wind energy integration", EEEIC 2012, Venice, Italy.

[12] M. Musavi, D. Chamberlain, Q. Li. "Overhead conductor dynamic thermal rating measurement and prediction", IEEE Conference on Smart Measurements for Future Grids, 2011. 
[13] L.M. Keselman, Y. Motlis. "Application of the ruling span concept for overhead lines in mountainous terrain", IEEE Transactions on Power Delivery 13 (1998).

[14] IEEE WG on Thermal Aspects of Overhead Conductors. "Limitations of the Ruling Span Method for Overhead Line Conductors at High Operating Temperatures", IEEE PWRD, 12 (1997).

[15] M. Keshavarzian, C.H. Priebe. "Sag and tension calculations for overhead transmission lines at high temperatures-modified ruling span method", IEEE Transactions on Power Delivery, 15 (2000).

[16] CIGRE TF B2.43, TB 601. "Guide for thermal rating calculations of overhead lines", 2014.

[17] CIGRE TF B2.12.3, TB 324. "Sag-tension calculation methods for overhead lines", 2007.

[18] "IEEE Standard for Calculating the Current-Temperature of Bare Overhead Conductors", IEEE Std. 738-2006.

[19] P. Pelacchi, D. Poli. "Thermo-mechanical model of multi-span overhead transmission lines equipped with high-temperature low-sag conductors", International Review on Modelling and Simulations, IREMOS 8 (2015).

[20] P. Pelacchi, D. Poli. "A novel thermo-mechanical model to assess the dynamic thermal rating of multi-span overhead transmission lines", Periodica Polytecnica Electrical Engineering and Computer Science, 59 (2015).

[21] I. Zamora, A.J. Mazon, P. Eguia, R. Criado, C. Alonso, J. Iglesias, J.R. Saenz. "High-temperature conductors: a solution in the uprating of overhead transmission lines", Proceedings of IEEE Power Tech, Porto, Portugal, 2001.

[22] CIGRE B2-AG-06. "Types and Uses of High Temperature Conductors."

[23] F. Bassi, G. Giannuzzi, M. Giuntoli, P. Pelacchi, D. Poli. "Mechanical behaviour of multi-span overhead transmission lines under dynamic thermal stress of conductors due to power flow and weather conditions", International Review on Modelling and Simulations, IREMOS 6 (2013).

[24] F. Bassi, G. Giannuzzi, M. Giuntoli, P. Pelacchi, D. Poli. "Thermomechanical dynamic rating of OHTL: applications to Italian lines", CIGRE Session 2014, Paris, 24-29 August 2014. 